\title{
Article \\ Effect of Spray Distance and Powder Feed Rate on Particle Velocity in Cold Spray Processes
}

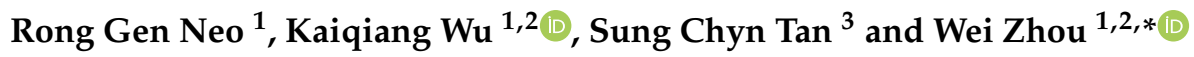 \\ 1 Rolls-Royce@NTU Corporate Laboratory, Nanyang Technological University, 65 Nanyang Drive, \\ Singapore 637460, Singapore; ronggen.neo@ntu.edu.sg (R.G.N.); KAIQIANG001@e.ntu.edu.sg (K.W.) \\ 2 School of Mechanical and Aerospace Engineering, Nanyang Technological University, 50 Nanyang Avenue, \\ Singapore 639798, Singapore \\ 3 Rolls-Royce Singapore Pte. Ltd., 1 Seletar Aerospace Crescent, Singapore 797575, Singapore; \\ sungchyn.tan@rolls-royce.com \\ * Correspondence: wzhou@cantab.net or mwzhou@ntu.edu.sg
}

Citation: Neo, R.G.; Wu, K.; Tan, S.C.; Zhou, W. Effect of Spray Distance and Powder Feed Rate on Particle Velocity in Cold Spray Processes. Metals 2022, 12, 75. https://doi.org/ $10.3390 /$ met12010075

Academic Editor: Pasquale Cavaliere

Received: 1 December 2021

Accepted: 31 December 2021

Published: 3 January 2022

Publisher's Note: MDPI stays neutral with regard to jurisdictional claims in published maps and institutional affiliations.

Copyright: (c) 2022 by the authors. Licensee MDPI, Basel, Switzerland. This article is an open access article distributed under the terms and conditions of the Creative Commons Attribution (CC BY) license (https:// creativecommons.org/licenses/by/ $4.0 /)$.

\begin{abstract}
Cold spray technology using micron-sized particles to produce coatings is increasingly used for reparative tasks in various industries. In a cold spray setup, the gun is usually connected to a robotic arm to deposit coatings on components with complex geometries. For these components, the standoff distance used in the cold spray process has to be large enough for easy maneuverability of the gun around a small radial feature. However, a small standoff distance is commonly found in most studies, which is thought to prevent a velocity drop of the particles over a larger distance. Here, a study was carried out by measuring the Inconel 625 particle velocity at different spray distances, ranging from 3 to $40 \mathrm{~cm}$. The highest average velocity of $781 \mathrm{~m} / \mathrm{s}$ was found at a spray distance of $8 \mathrm{~cm}$. Furthermore, a study with varying powder feed rates was also conducted. An increase in the powder feed rate was found to have a minimal effect on the particle velocity. Inconel 625 coatings deposited at the optimum standoff distance $(8 \mathrm{~cm})$ were found to have low porosity and high hardness. The results in this study demonstrate that a larger standoff distance can be applied without a significant drop in velocity for cold spray applications requiring high maneuverability.
\end{abstract}

Keywords: cold spray; particle velocity; powder feed rate; spray distance; standoff distance; Inconel 625

\section{Introduction}

Cold spray is a solid-state deposition technology capable of repairing metallic components. This technology has been widely used in industry for repair and restoration purposes [1]. In a cold spray process, micron-sized metallic particles are accelerated to supersonic speed via a converging-diverging de Laval nozzle and impact the damaged parts to form metallic coatings [2]. The main cold spray application setup normally consists of the cold spray gun attached to a robotic arm. This is to allow repair jobs to be performed on components with complex geometries by moving the robotic arm in a programmed path. Complex geometries with small radial features pose a great challenge for the cold spray gun maneuverability since the cold spray gun nozzle is normally bulky, being tens of millimeters in size. To overcome this challenge, it is practical to increase the standoff distance between the damaged part and the gun nozzle. However, studies on particle velocity at larger spray distances are still lacking.

For cold spray deposition, increasing the standoff distance was generally thought to result in a lower particle speed due to the drag force exerted on the particle. As such, small standoff distances such as $2.5 \mathrm{~cm}[3,4], 3 \mathrm{~cm}[5,6], 3.5 \mathrm{~cm}[7], 4 \mathrm{~cm}[8,9], 5 \mathrm{~cm}[10]$, and $6 \mathrm{~cm}$ [11] were used to achieve a deposition on the substrate. However, a study by Pattison et al. in 2008 found that the standoff distance should be optimized to achieve a high particle velocity and deposition efficiency [12]. In their study, computational and experimental studies were conducted to understand the effect of standoff distance. They 
reported that a small standoff distance $(<6 \mathrm{~cm})$ will reduce the particle velocity and deposition efficiency. This is due to a bow shock phenomenon occurring near the substrate surface caused by the free gas jet impingement, which slows down the particle velocity before impact. However, in their study, the range of distance considered for particle velocity measurement is only up to $7 \mathrm{~cm}$. Therefore, there is a clear need to understand how velocity changes with distance in order to achieve a high particle velocity during cold spray deposition.

A particle with high velocity does not necessarily translate into deposition onto a substrate. For successful deposition to occur, the particles have to travel at supersonic velocity higher than a critical velocity determined semi-empirically [2]. A velocity lower than the critical velocity leads to abrasion of the substrate.

Particle velocity can be increased by increasing the working temperature and pressure of the cold spray process gas [13]; using propelling gas with a smaller molecular mass, such as helium [14]; and incorporating an optimized nozzle design into the cold spray gun [15]. In addition, particle velocity can also be influenced by the powder feed rate in the nozzle, as reported by Meyer et al. [16]. By increasing the powder feed rate in the nozzle, the particle velocity decreases due to gas-particle interactions while traveling away from the nozzle outlet. Other studies also reported similar findings on the effect of powder feed rate and particle velocity $[17,18]$.

In addition, a study was conducted to visually observe the particle interactions during flight [19]. Particles were found to collide with each other and the nozzle wall, causing the particles to disperse away from the axial flow of the jet stream. However, the measurement equipment used is accompanied with a camera for image processing. It is challenging to measure particle speed through the images when large amounts of powders pass through the camera's field of view at higher powder feed rates.

In this paper, the effects of velocity change were studied at a wide range of spray distances and powder feed rates. The powder material used here is a nickel-based superalloy, Inconel 625, which is widely used in the aerospace industry. Cold spray parameters of working gas temperature and pressure were maximized to achieve a high particle velocity for each spray distance and powder feed rate. Measurements were done using a commercial device which utilizes a laser for its measurements. The experimental results show that there is a highest average velocity of $781 \mathrm{~m} / \mathrm{s}$ at a spray distance of $8 \mathrm{~cm}$, and particle velocity is almost constant at different powder feed rates. Cold spray coatings deposited at an $8 \mathrm{~cm}$ standoff distance were found to have low porosity and high hardness. The findings from this study are beneficial for future cold spray applications on repairing components with complex geometries.

\section{Materials and Methods}

Impact Spray System 5/11 (Impact Innovations GmbH, Rattenkirchen, Germany) was used to spray gas-atomized Inconel 625 powders (Sandvik Osprey Ltd., Sandviken, Sweden) with the cold spray parameters shown in Table 1 . The powder distribution is as follows: $\mathrm{D}_{10}=15 \mu \mathrm{m}, \mathrm{D}_{50}=30 \mu \mathrm{m}$, and $\mathrm{D}_{90}=45 \mu \mathrm{m}$. The powders traveled through a SiC nozzle in the cold spray gun with a $6 \mathrm{~mm}$ diameter nozzle exit. The nozzle has a design with an expansion ratio of 5.6 and a divergent section length of $160 \mathrm{~mm}$.

Table 1. Cold spray processing parameters used.

\begin{tabular}{cc}
\hline Parameter & Value \\
\hline Working gas & Nitrogen \\
Gas pressure & $4.5 \mathrm{MPa}$ \\
Gas temperature & $1050{ }^{\circ} \mathrm{C}$ \\
Powder feed rate & 5.45 to $92.65 \mathrm{~g} / \mathrm{min}$ \\
Spray distance & 3 to $40 \mathrm{~cm}$ \\
\hline
\end{tabular}


The sprayed powder velocity and diameter were measured using a cold spray meter (CSM EVOLUTION, Tecnar Automation Ltd., Quebec, Canada) with the capability of measuring particle diameters and velocities in the range of 10-300 $\mu \mathrm{m}$ and $10-1500 \mathrm{~m} / \mathrm{s}$. The measurement principle of the cold spray meter is the analysis of the electrical signal produced by the laser scattered by the particles during flight. In the measurement process, the laser is illuminated on the cold spray plume to produce a scattered laser reflected from the particles [13]. A photomask with two vertical slits is placed in front of the detector to detect the scattered laser for the particle diameter and velocity analyses. A twin peak electrical signal is generated for analyses in the control module. In the control module, the particle velocity is determined from the equation below:

$$
v=\frac{s}{t} \times \text { lens optical magnification }
$$

where $v$ is the measured particle velocity, $s$ is the distance between the two vertical slits in the photomask, and $t$ is the time difference between the twin peaks in the electrical signal. Likewise, the measurement of the particle diameter is determined from the energy radiated from individual particles. The energy is obtained from the area integral of the twin peaks, and the particle diameter can be calculated from the equation below:

$$
D_{p}=\sqrt{\frac{E}{D_{c}}}
$$

where $D_{p}$ is the particle diameter, $E$ is the energy irradiated by the particles obtained from the twin peaks, and $D_{c}$ is the diameter coefficient, which is calibrated prior to measurement.

Furthermore, simulations of particle velocity and critical velocity at different spray distances were conducted using the web-based software by Kinetic Spray Solutions (KSS), Buchholz, Germany [5]. Coating porosity, powder morphologies and deformation were observed using a scanning electron microscope (SEM) (JOEL JSM-5600LV, JOEL Ltd., Tokyo, Japan), a field emission SEM (JOEL JSM-7600f, JOEL Ltd., Tokyo, Japan), and a laser confocal microscope (Olympus, LEXT OLS4100, Tokyo, Japan). Microhardness of the coating and substrate was measured using a Vickers hardness tester (FM-300e, Future-tech Corp., Kawasaki, Japan) with an indentation load of 200 g.

\section{Results}

\subsection{Particle Velocity at Different Spray Distances}

The spray distance was measured from the cold spray gun nozzle exit to the measurement point with no substrate present, as shown in Figure 1a. The cold spray gun was positioned perpendicularly to the laser illumination axis for accurate measurement of the particle velocity, as illustrated in Figure 1b. Spray distances of 3, 6, 8, 10, 12, 20, 30, and $40 \mathrm{~cm}$ were chosen for velocity measurement, and the measurement results are shown in Figure 2. The average velocities in Figure 2a were calculated from the individual particle velocity measurements at their corresponding spray distances, as shown in Figure $2 b-j$. Simulated particle and critical velocity were also included in Figure $2 \mathrm{a}$ to observe and compare the trends. 


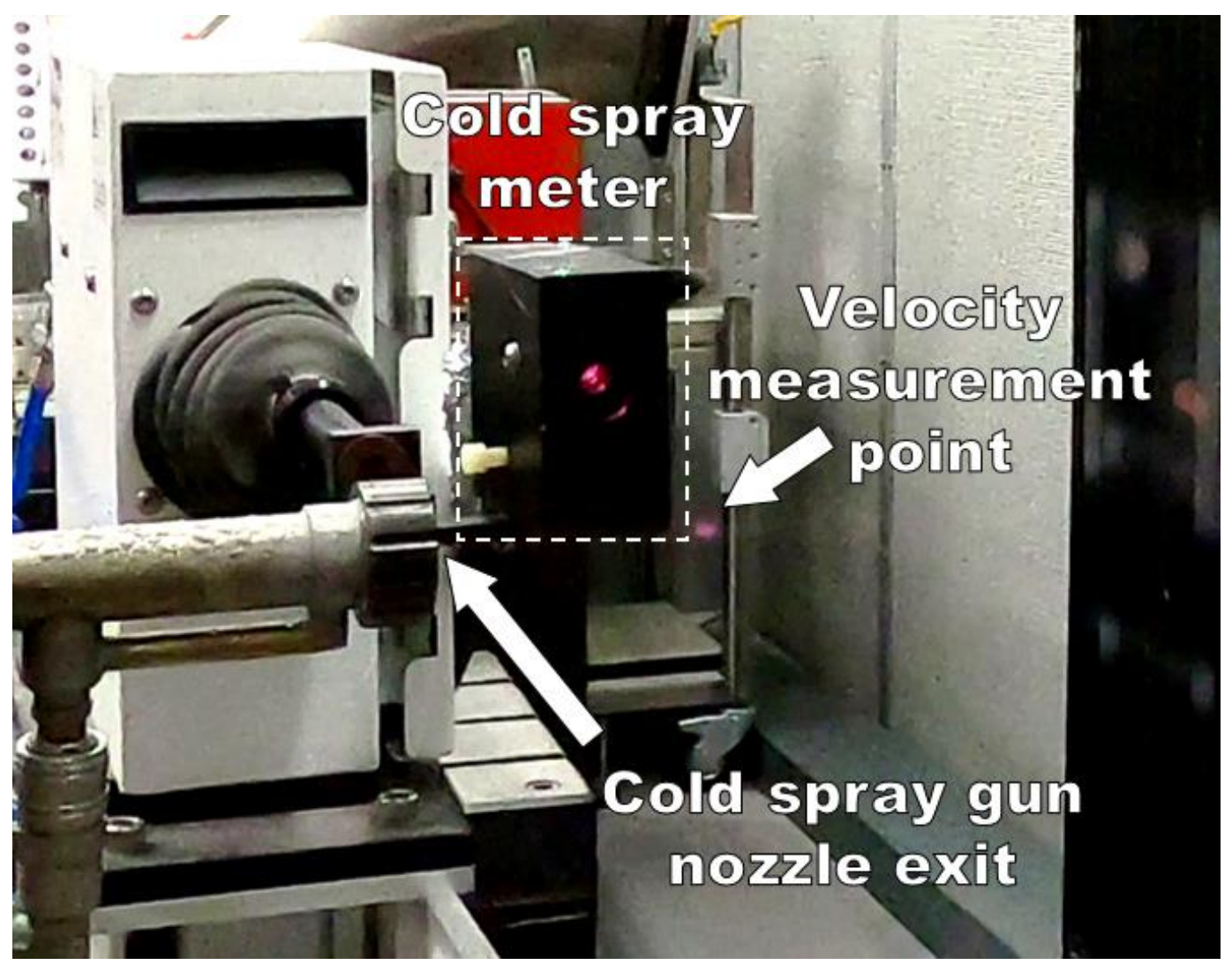

(a)

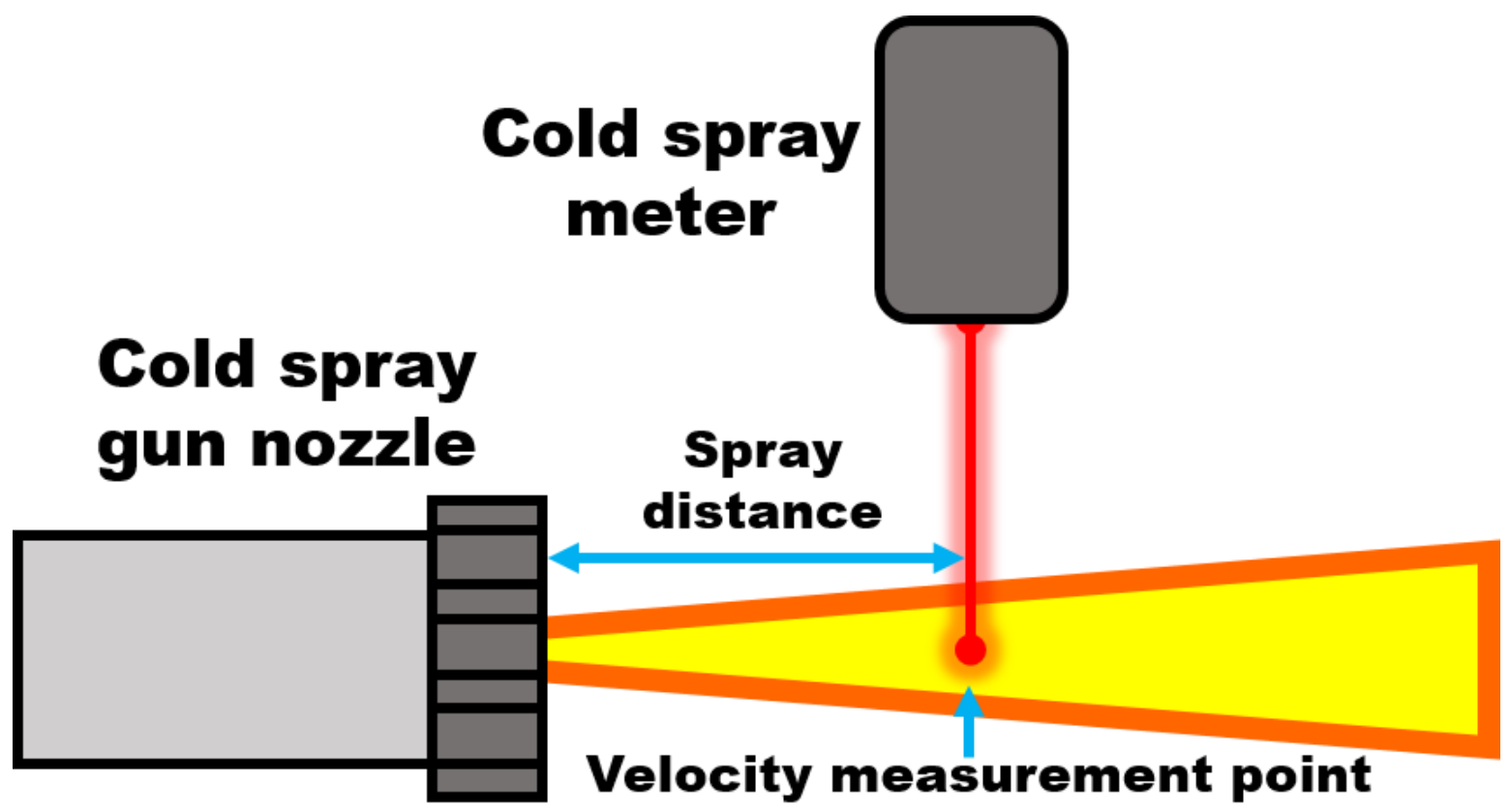

(b)

Figure 1. Position of the cold spray gun with respect to the cold spray meter during cold spray operation. The gun is placed perpendicularly to the cold spray meter measurement point and moved to the desired spray distance to perform velocity measurement. The spray distance is measured from the cold spray gun nozzle exit to the velocity measurement point as shown in (a) actual experimental setup and (b) illustration. 

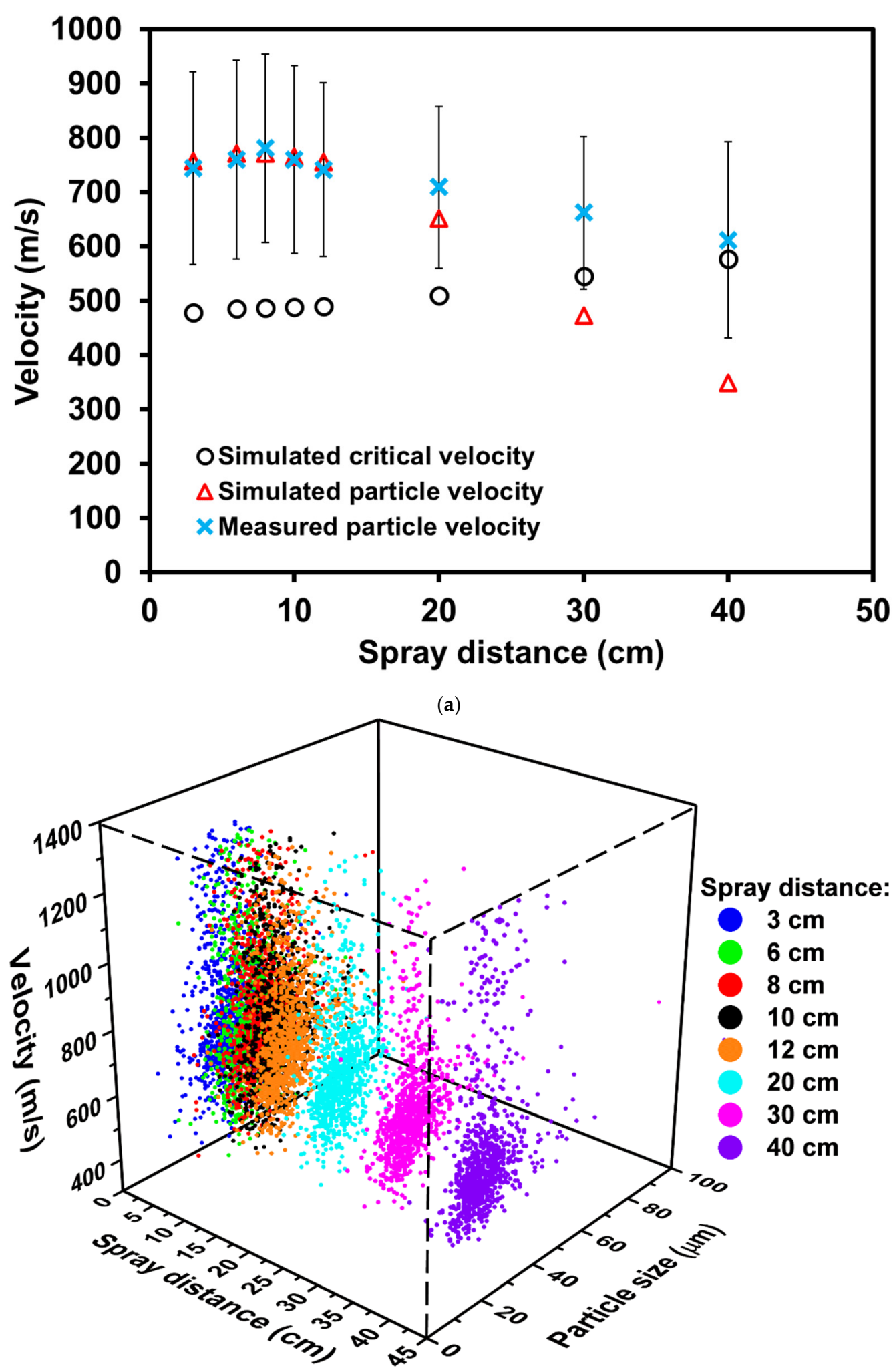

(b)

Figure 2. Cont. 


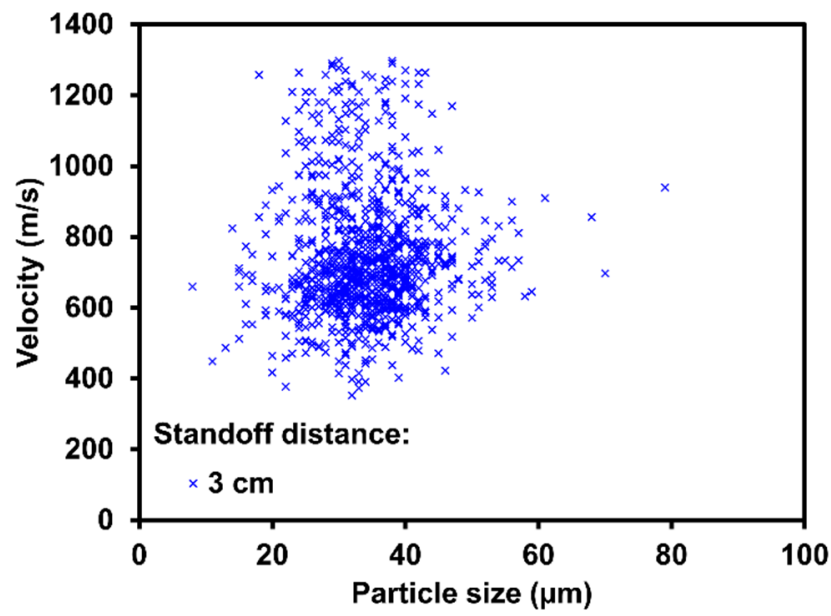

(c)

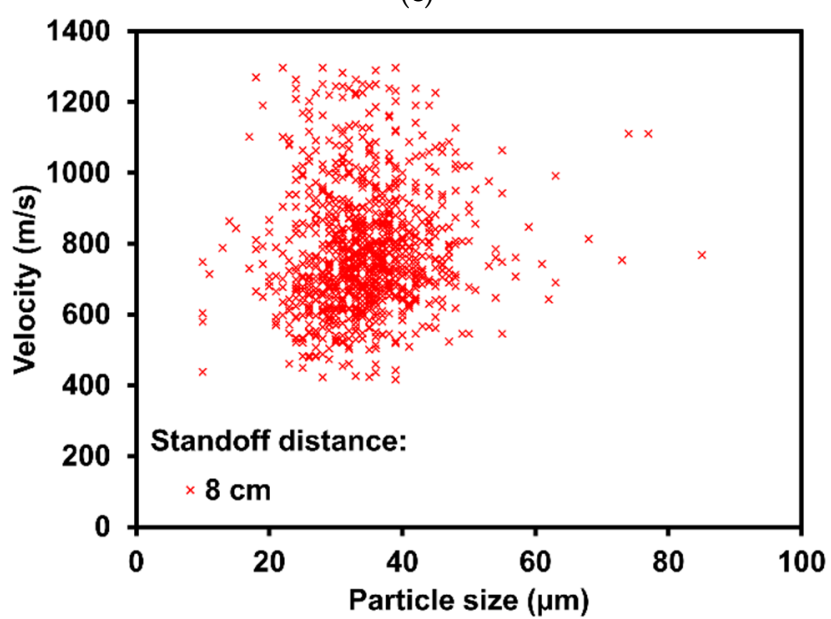

(e)

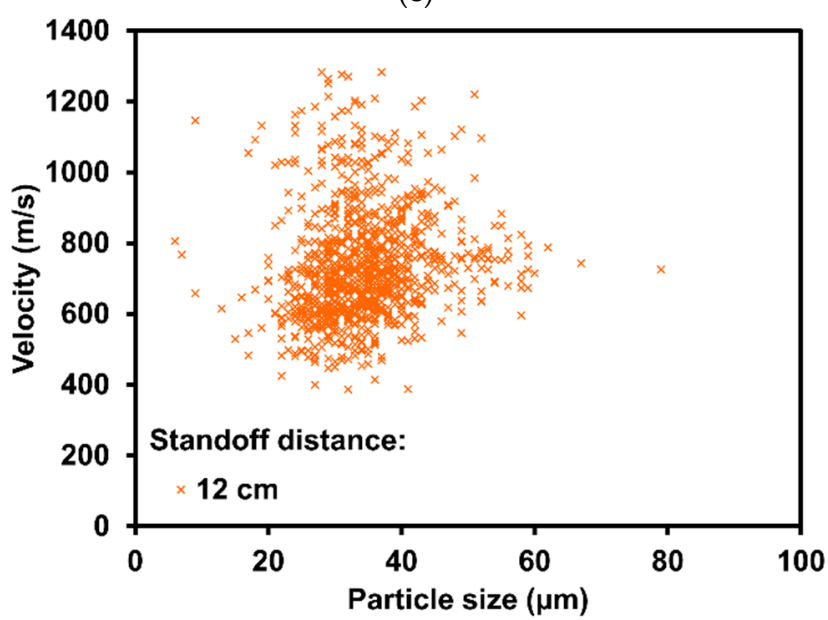

(g)

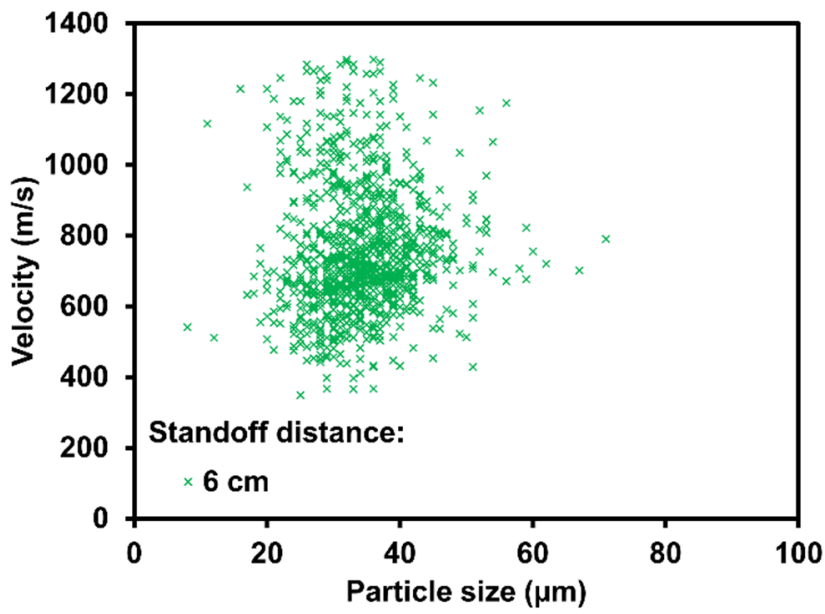

(d)

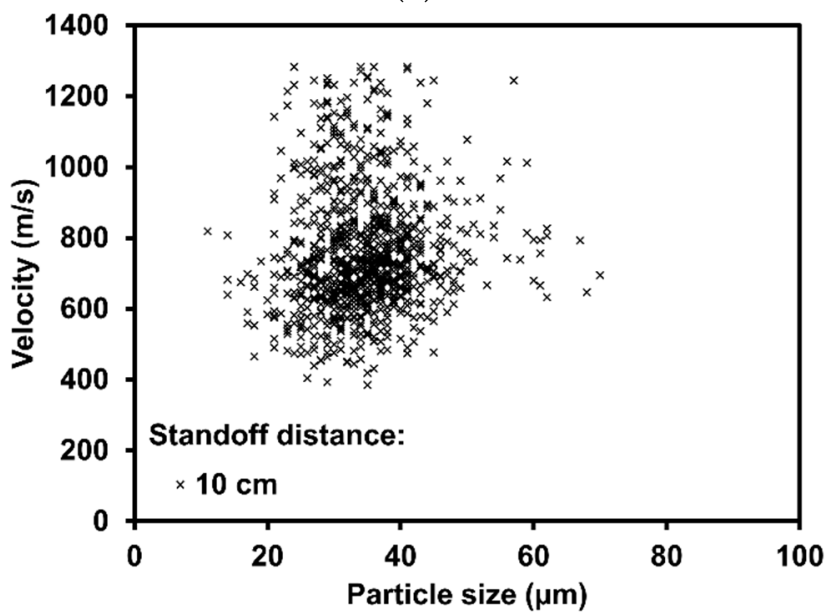

(f)

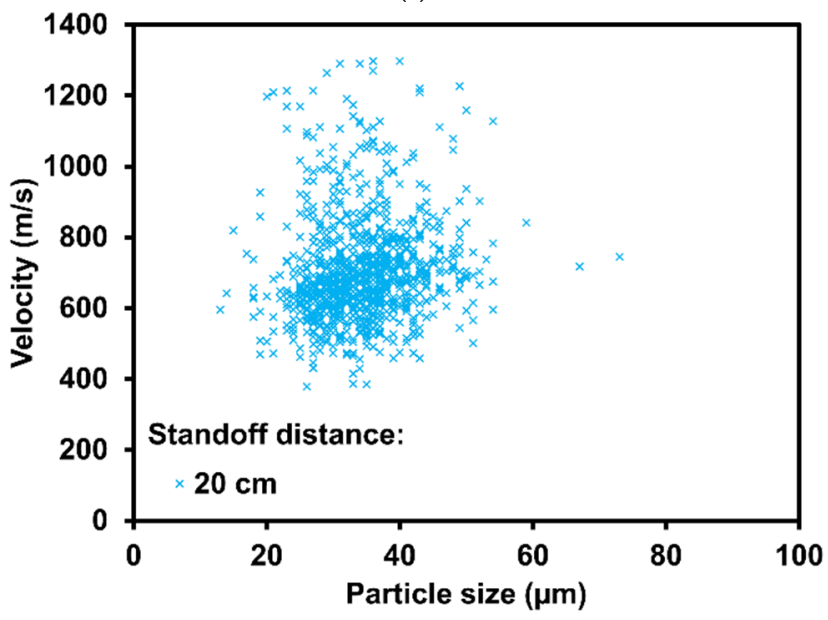

(h)

Figure 2. Cont. 


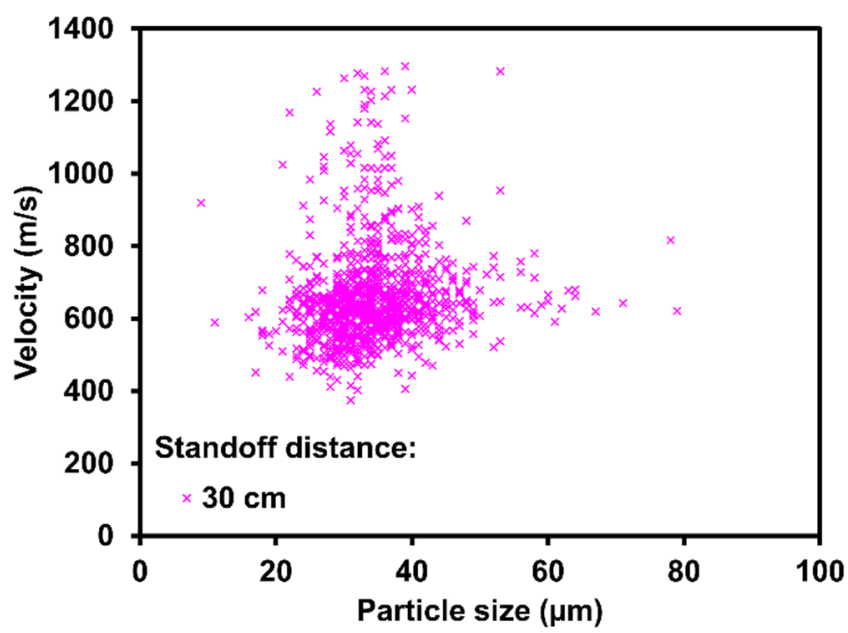

(i)

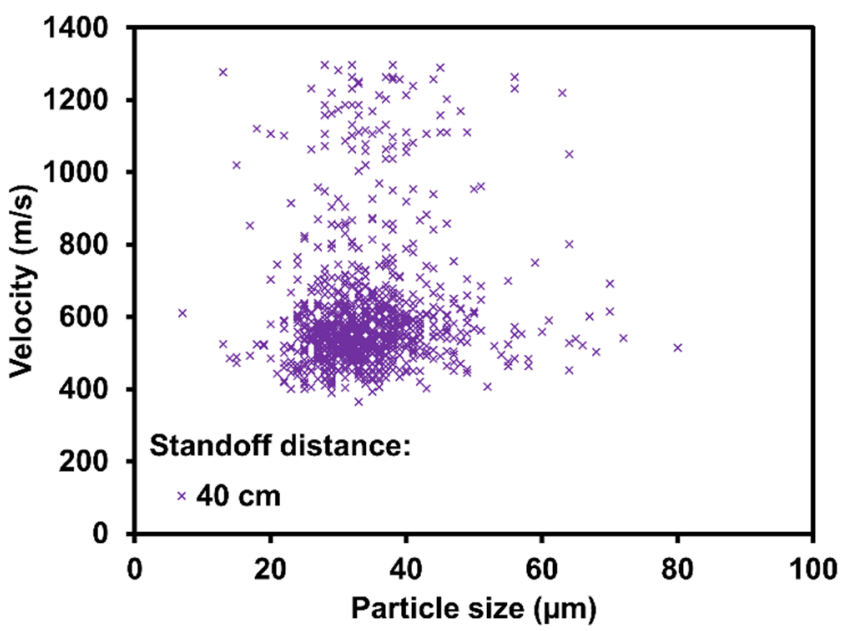

(j)

Figure 2. (a) Velocity measurement and simulation results for Inconel 625 at different spray distances. (b) Individual particle velocity corresponding to the particle size and spray distance in 3D graphical format and in 2D graphical format for (c) $3 \mathrm{~cm},($ d) $6 \mathrm{~cm},(\mathbf{e}) 8 \mathrm{~cm},(\mathrm{f}) 10 \mathrm{~cm},(\mathrm{~g}) 12 \mathrm{~cm},(\mathrm{~h}) 20 \mathrm{~cm}$, (i) $30 \mathrm{~cm}$, and (j) $40 \mathrm{~cm}$ spray distances.

The velocity measurements of the powders appear to display an optimum spray distance to achieve a highest average velocity. The optimum spray distance for Inconel 625 powders is $8 \mathrm{~cm}$, with a highest average velocity of $781 \mathrm{~m} / \mathrm{s}$. Similarly, optimum distance obtained from the KSS software simulation is $8 \mathrm{~cm}$ as well. The simulated critical velocity is included as a guide, and above it, a particle will likely achieve a successful bond onto the substrate [2] For example, a further increase in the spray distance to greater than $40 \mathrm{~cm}$ will result in the measured particle velocity becoming lower than the critical velocity, and this may have an effect on the particle deposition. A large error bar in the measurement is due to the large velocity variation, as shown in Figure $2 b-j$.

\subsection{Particle Velocity at Different Powder Feed Rates}

Powder feed rate supplied to the cold spray gun is controlled by adjusting the disk rotating speed in the powder feeder. Powder feed rates of 5.45-92.65 g/min were used for the Inconel 625 powders. The upper limit of the powder feed rate corresponds to the maximum disk rotational speed. The spray distance for this study is the optimum spray distance of $8 \mathrm{~cm}$, as determined from the previous section. The velocity variation with different feed rates is not significant in comparison to the spray distance study, as shown in Figure 3a. Furthermore, the distribution of the individual particle velocity corresponding to the particle size is similar for every feed rate, as shown in Figure $3 b-g$. 

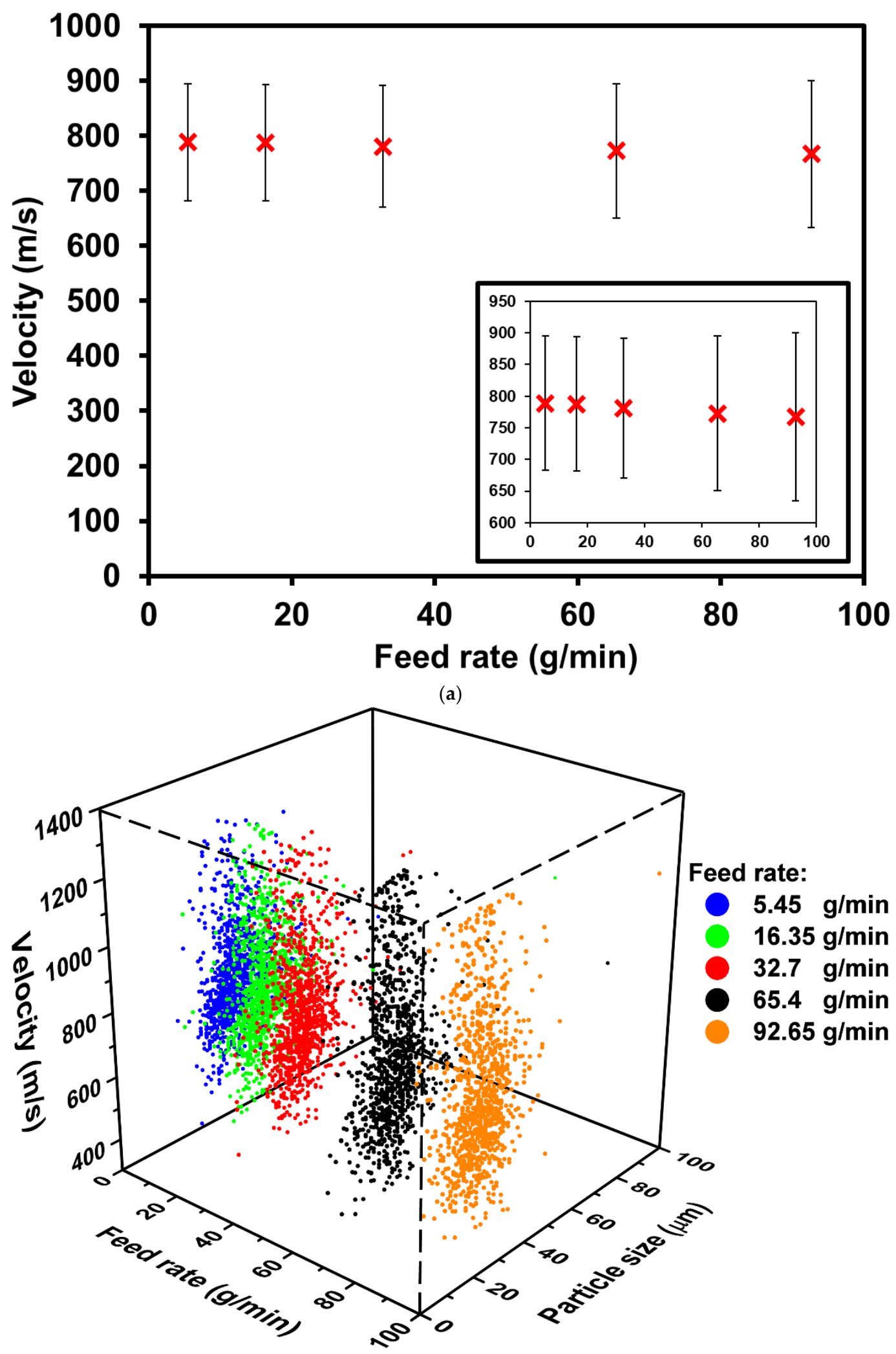

(b)

Figure 3. Cont. 


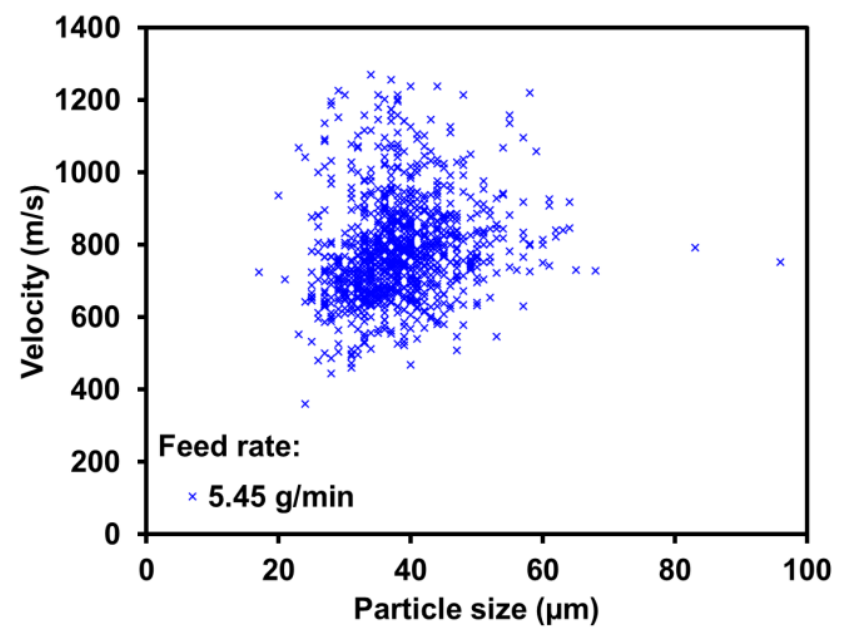

(c)

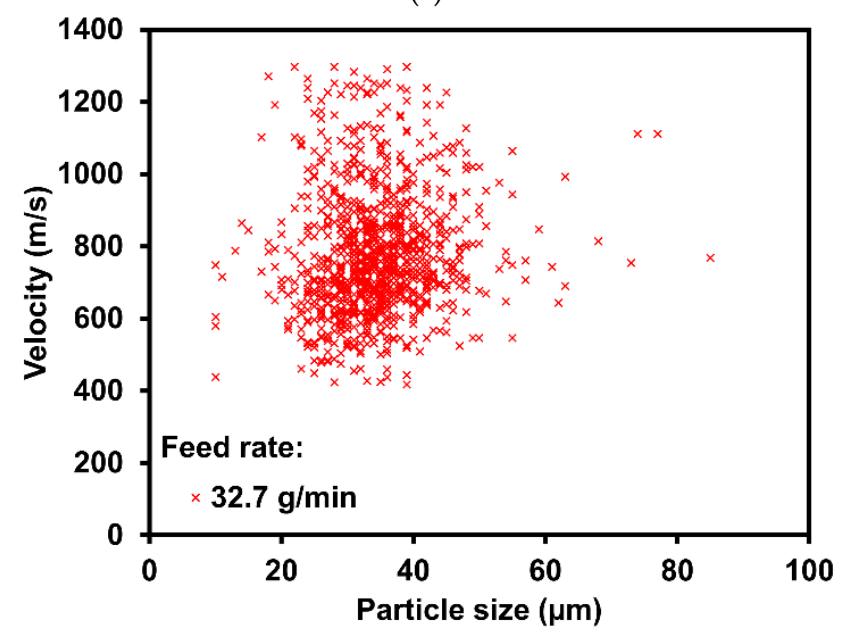

(e)

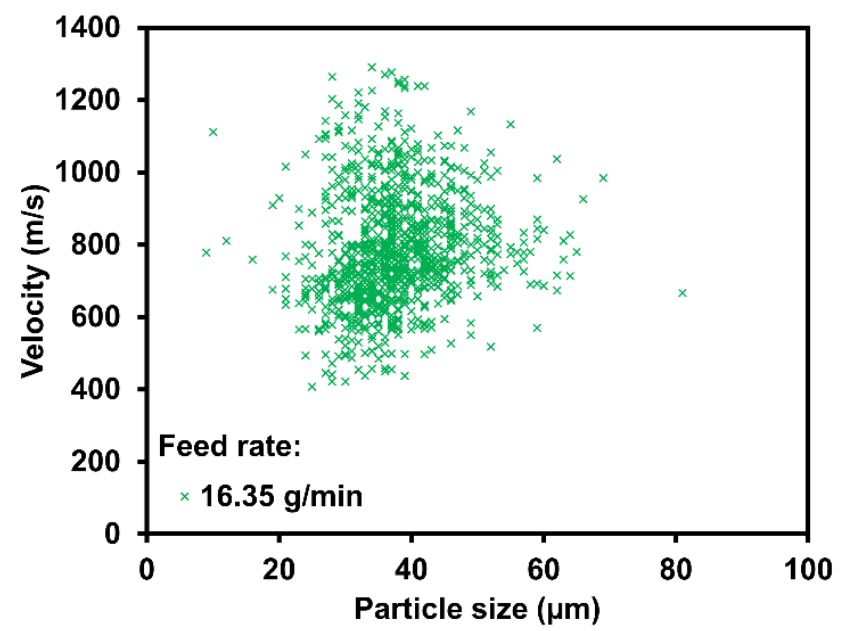

(d)

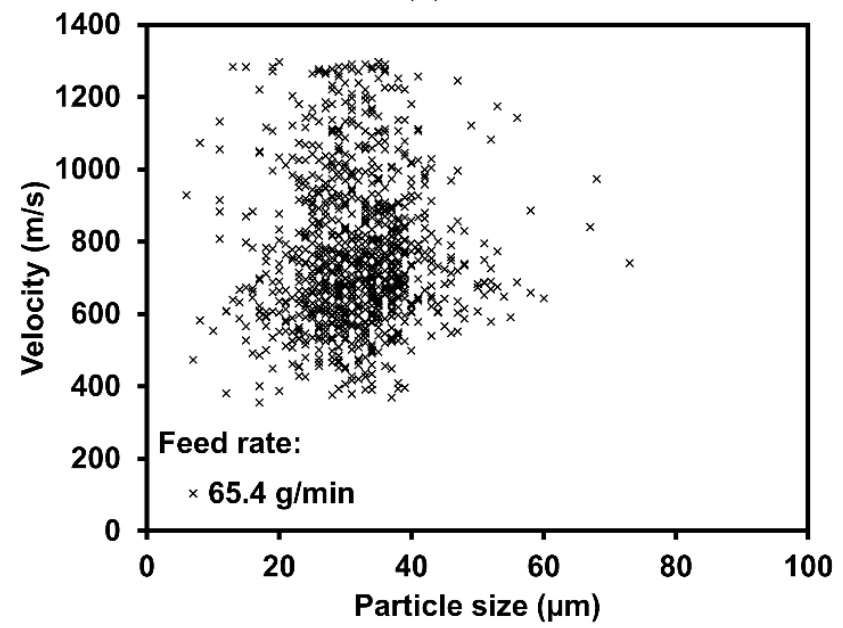

(f)

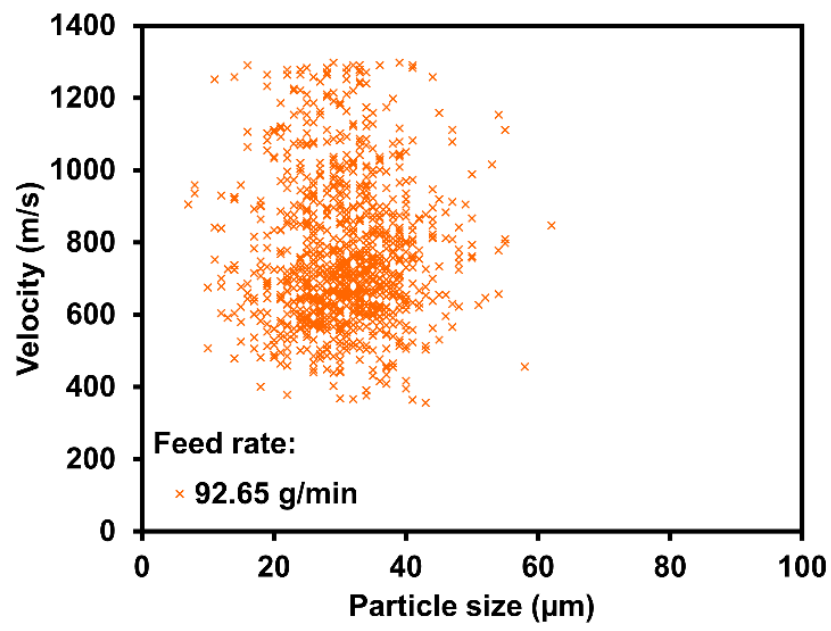

$(\mathrm{g})$

Figure 3. (a) Velocity measurement at different powder feed rates. The velocity change is not significant by changing the powder feed rate. Inset figure shows the magnified graph to clearly observe the trend. (b) Individual particle velocity measurement corresponding to the particle size and feed rate in 3D graphical format and in 2D graphical format for (c) $5.45 \mathrm{~g} / \mathrm{min}$, (d) $16.35 \mathrm{~g} / \mathrm{min}$, (e) $32.7 \mathrm{~g} / \mathrm{min}$, (f) $65.4 \mathrm{~g} / \mathrm{min}$, and (g) $92.65 \mathrm{~g} / \mathrm{min}$ feed rates. 


\section{Discussion}

Small standoff distance between the cold spray gun and the substrate poses a challenge to maneuvering the gun around a small radial feature. The results presented in this study show that the distance can be further increased without sacrificing too much of the particle velocity to achieve successful bonding for cold spray applications. The velocity measurement results presented in Figure 2a show that Inconel 625 particle velocities from $3-40 \mathrm{~cm}$ are still above the simulated critical velocity. This indicates that a wider standoff distance range is available to choose from for cold spray applications. Furthermore, in Figure 2a, the simulated critical velocity increases at large distances because the particle's temperature drops when exposed longer to the air. The particle requires a higher velocity to compensate for the loss in heat energy for successful bonding, as temperature is an important parameter for a successful cold spray bond to occur [20,21].

Another interesting observation from the results presented in Figure 2 is the existence of an optimum spray distance to achieve a high average particle velocity. It is generally known that any projectiles fired from a barrel will experience a drop from their highest velocity at the barrel exit due to air resistance. This is why a small standoff distance is preferred in cold spray applications $[3,4,7-11,22,23]$. However, in a cold spray process, the working gas is continuously fed through the system and causes the particle velocity to continue to increase even after it passes the nozzle exit. This is due to the fact that the particle continues to accelerate outside the nozzle [12], and the findings in this study support that. On the other hand, the particle velocity decreases from the highest average velocity at larger spray distances due to the air resistance experienced by the particles and the pressure loss from the gas stream. The particle velocity decreases in a linear manner at $11 \mathrm{~m} / \mathrm{s}$ per centimeter beyond the optimum spray distance. In addition, the trends in velocity at different spray distances for other metallic powders were found to be similar to those seen in research done by Pattison et al. [12]. In their study, copper and titanium powders were found to continue to accelerate outside of the nozzle. The velocity was found to keep increasing at larger spray distances, but this is likely due to the fact that they used a small range of distance of only up to $7 \mathrm{~cm}$.

Velocity distribution of the particles was found to be similar at larger spray distances, even with a decrease in velocity. As presented in Figure $2 j$, considerable amounts of powders are still in the upper range of the velocity distribution at $40 \mathrm{~cm}$. For example, about $12.6 \%$ of particles are above $1000 \mathrm{~m} / \mathrm{s}$ at the optimum spray distance of $8 \mathrm{~cm}$ in Figure $2 \mathrm{e}$, and at $40 \mathrm{~cm}$, the amount is quite similar, with $7.1 \%$ of particles above $1000 \mathrm{~m} / \mathrm{s}$ in Figure 2j. This may be due to the irregular Inconel 625 powder morphology, as shown in the SEM image (Figure 4). An irregularly shaped particle has a larger drag force on it and is able to achieve a higher velocity over large distances [24].

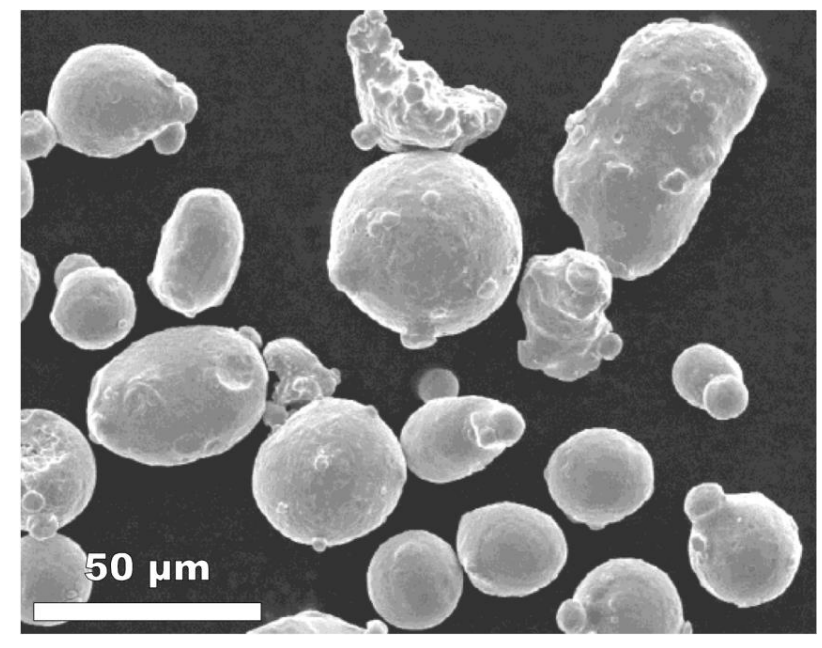

Figure 4. SEM micrograph showing irregular morphology of the Inconel 625 powders. 
The particle velocity effect from the variation of the powder feed rate is not significant, as shown in Figure 3. For Inconel 625 powders, the drop in velocity by increasing feed rate is small, from $789 \mathrm{~m} / \mathrm{s}$ at $5.45 \mathrm{~g} / \mathrm{min}$ to $767 \mathrm{~m} / \mathrm{s}$ at $92.65 \mathrm{~g} / \mathrm{min}$, or a decrease of $2.77 \%$. The velocity decreases by $0.3 \mathrm{~m} / \mathrm{s}$ for an increase of $1 \mathrm{~g} / \mathrm{min}$ in the powder feed rate. The decrease in velocity at high feed rates is less significant due to its density, as a high-density powder such as Inconel 625 , with a density of $8.25 \mathrm{~g} / \mathrm{cm}^{3}$, is less strongly affected by the turbulence flow of the gas jet, and this prevents it from being dispersed away from the jet stream $[18,19]$.

A further experiment was carried out to cold spray a single particle of Inconel 625 powder onto an Inconel 625 substrate. The cold spray process was carried out at a large standoff distance of $20 \mathrm{~cm}$, and successful deposition was achieved, as shown in Figure 5a,b. The particle is analyzed using the single particle impact evaluation method, as described in our previous work [25]. A pronounced jetting is formed after the particle impact on the substrate, as indicated from the height profile in Figure 5b, where the outermost circumference of the deformed particle is deflected upwards and has a larger profile than the inner circumference. Previous research has shown that a jetting phenomenon indicates a successful bond between the particle and the substrate $[2,20]$. This shows the feasibility of performing cold spray at a large standoff distance. Furthermore, the deposition efficiency calculated using the KSS software shows that the deposition efficiency at $20 \mathrm{~cm}$ is $95 \%$, as shown in Figure 5c. The deposition efficiency at spray distances from 3 to $12 \mathrm{~cm}$ is $99-100 \%$.
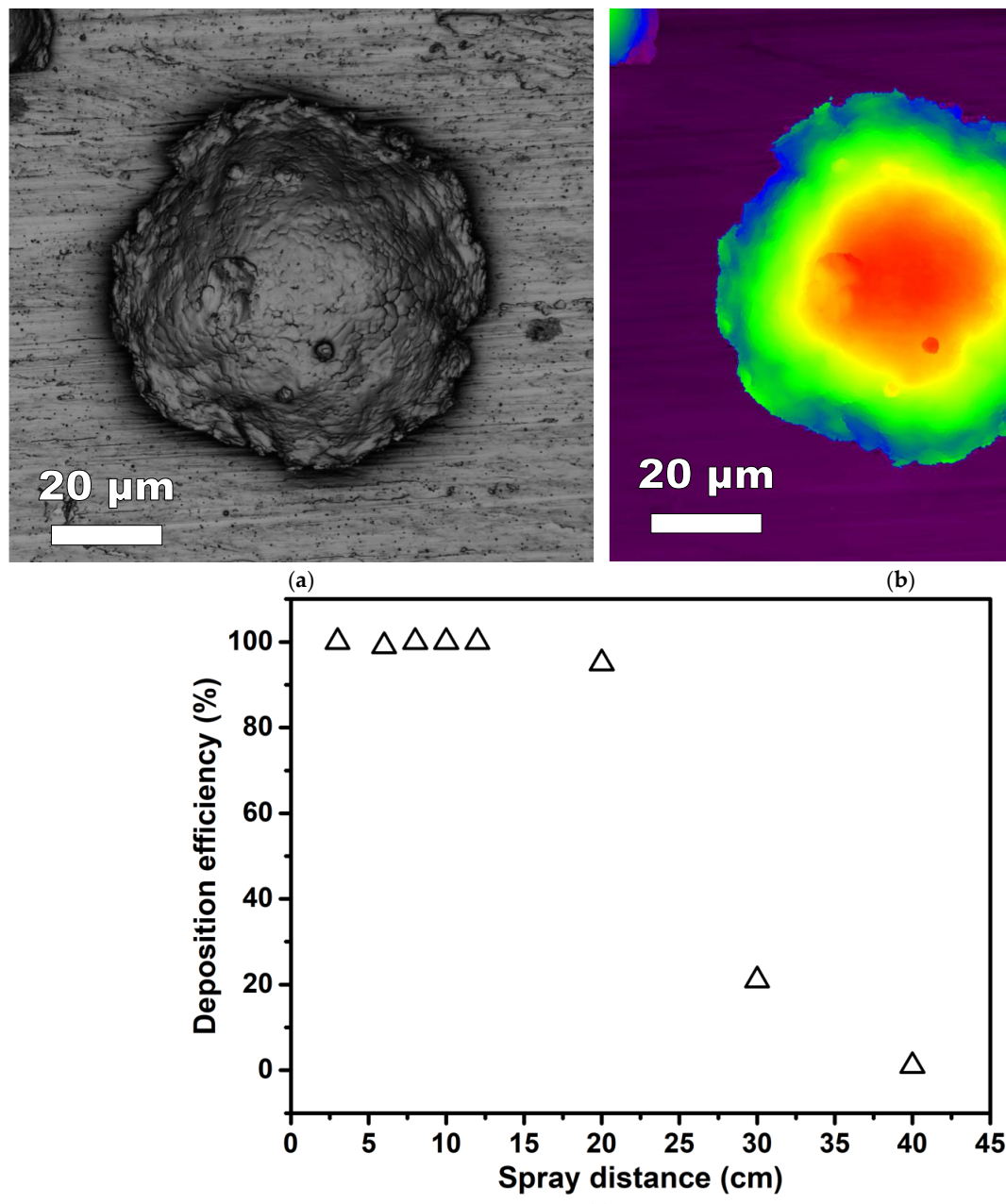

(c)

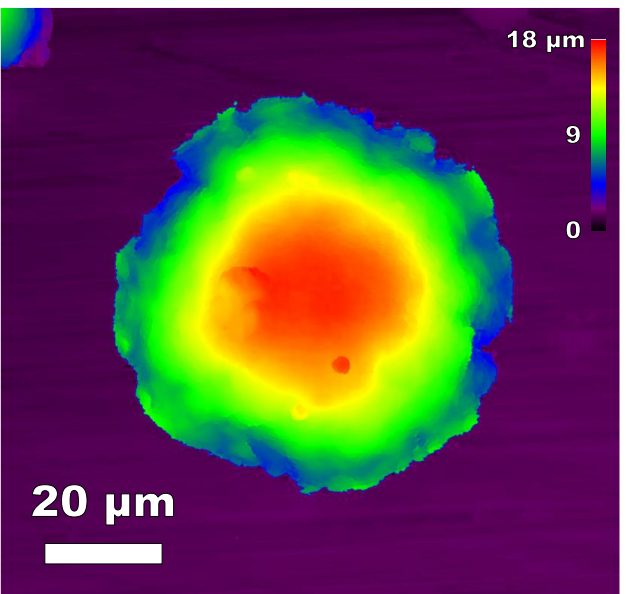


Inconel 625 cold spray coatings at different standoff distances of 3 and $8 \mathrm{~cm}$ were also deposited on Inconel 625 substrate to understand the coating quality. The basic cold spray parameters used are the same as those shown in Table 1. The powder feed rate used was $32.7 \mathrm{~g} / \mathrm{min}$, and substrate traverse speed was $500 \mathrm{~mm} / \mathrm{s}$. After the samples were ground and polished, the porosity and hardness measurements were done, and the results are presented in Figure 6. From Figure 6a, the average porosity value for the $8 \mathrm{~cm}$ standoff distance is lower than the commonly used $3 \mathrm{~cm}$ standoff distance. A similar observation was found from the microscopic images in Figure 7. This observation is consistent with Figure 2a, which shows that the highest average velocity occurs at an $8 \mathrm{~cm}$ spray distance. Furthermore, the hardness values were found to be similar for both coatings, as shown in Figure $6 b$, indicating that the deformation of the particles after the cold spray process at the $8 \mathrm{~cm}$ standoff distance is comparable with the $3 \mathrm{~cm}$ standoff distance.

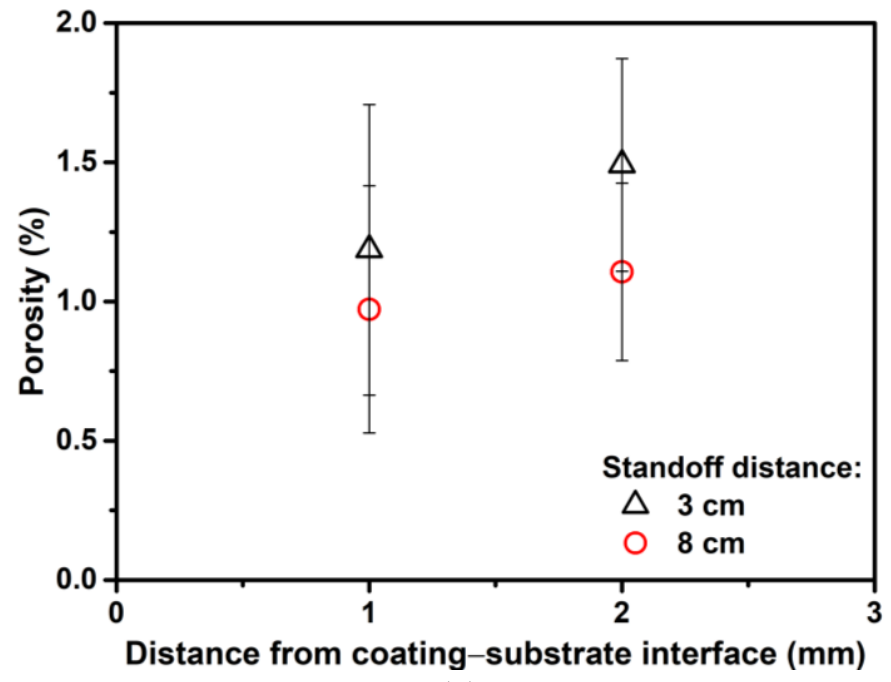

(a)

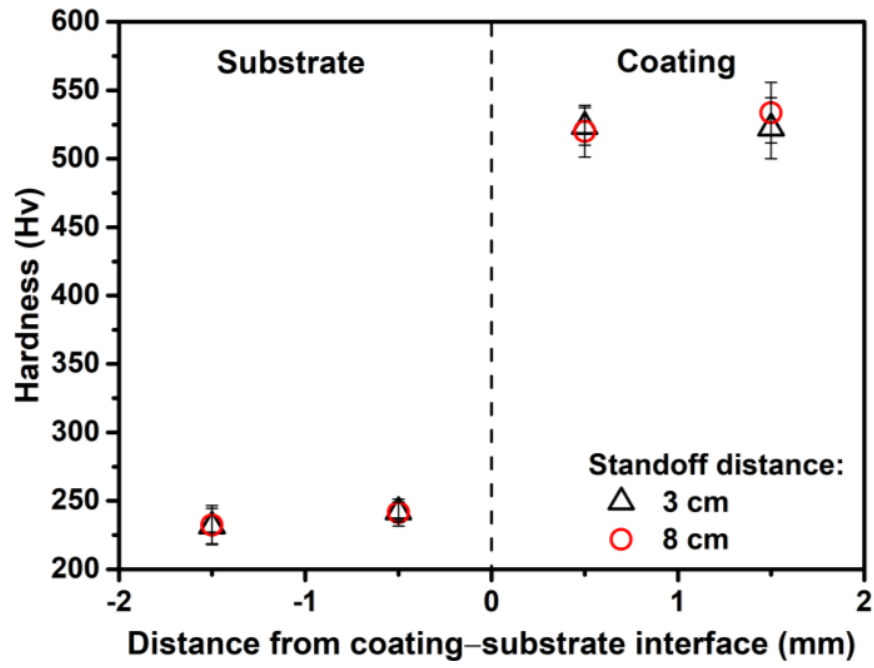

(b)

Figure 6. (a) Porosity in the coatings and (b) hardness results of Inconel 625 coating at 3 and $8 \mathrm{~cm}$ standoff distances.

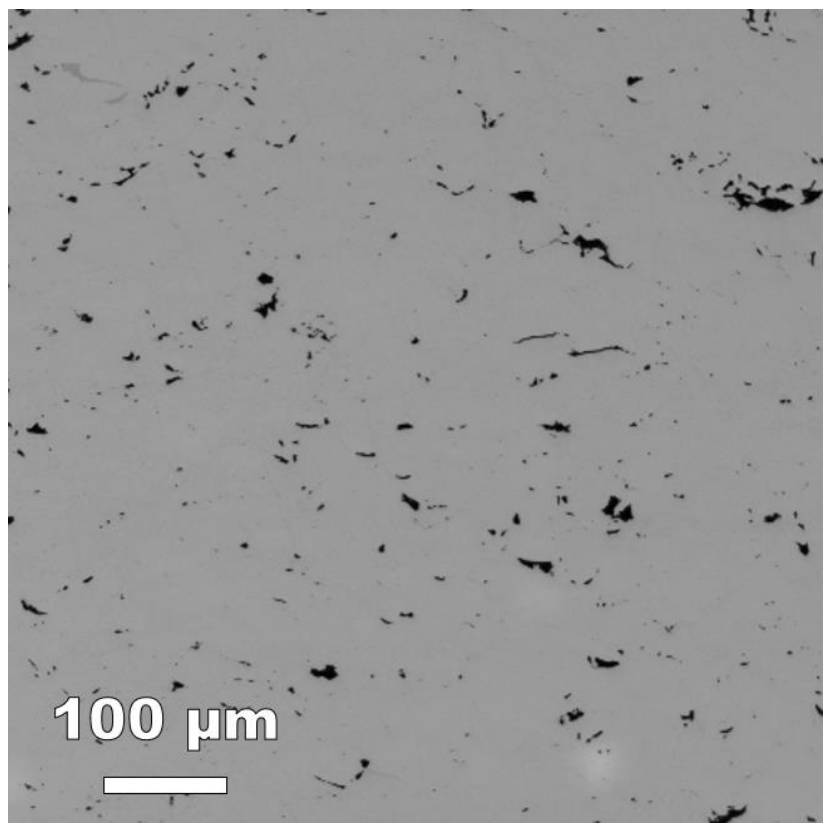

(a)

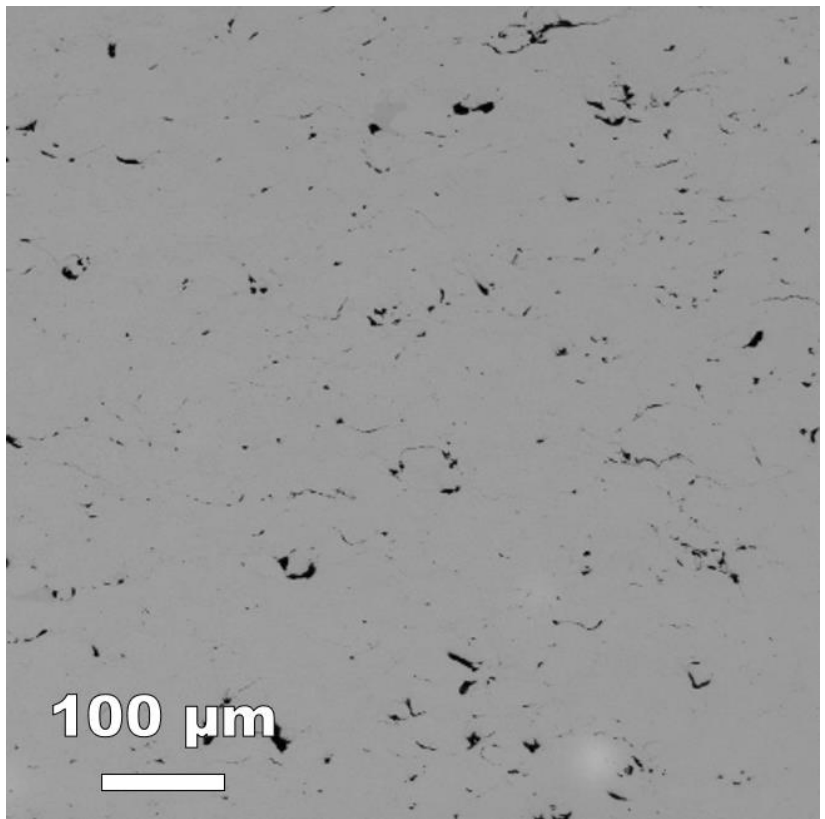

(b)

Figure 7. Optical images showing porosity in Inconel 625 coating at (a) 3 and (b) $8 \mathrm{~cm}$ standoff distances. 
By using the same powder, cold spray system, and parameters within the range discussed in this paper (standoff distance of $3 \mathrm{~cm}$, powder feed rate of $32.7 \mathrm{~g} / \mathrm{min}$ ), Inconel 625 coatings can be successfully deposited on different substrate materials, including Inconel 625 and Aluminum 6061. The deposited coatings on both substrates are shown in Figure 8, which was taken with the SEM operated in the backscattered electron (BSE) mode. In Figure 8a, the deformation of the Inconel substrate at the interface is limited, but the interface was found to be intimate, indicating a good bond between the coating and substrate, while for the Aluminum 6061 substrate in Figure 8b, the substrate was found to be largely deformed by the particles impacted at high velocity. Inconel 625 particles penetrated deep into the substrate due to the lower substrate hardness, leading to mechanical interlocking, which could enhance the bonding between the coating and the substrate. The particle velocity at the same standoff distance is the same for different substrates since the substrates do not affect the flight of the particle.

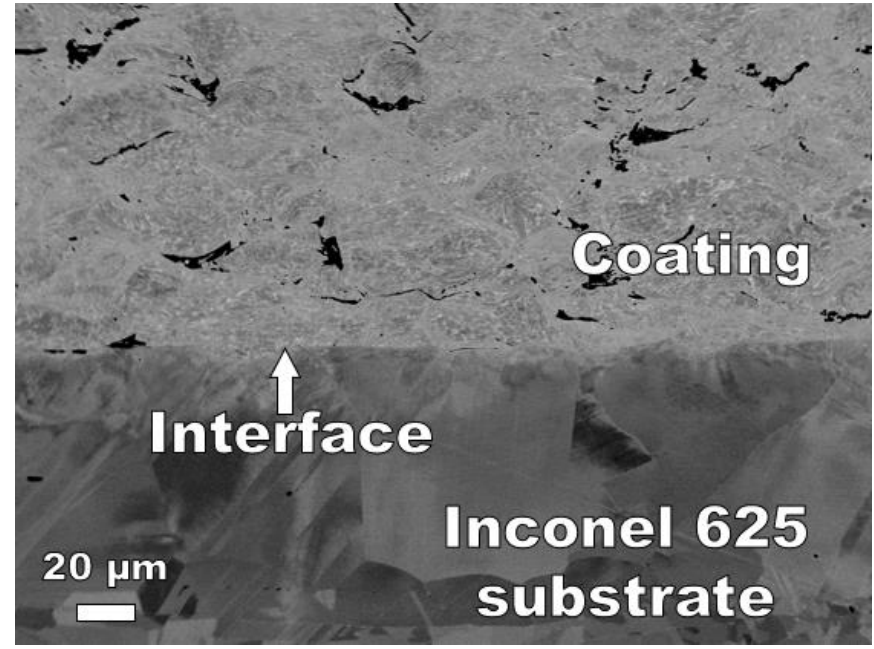

(a)

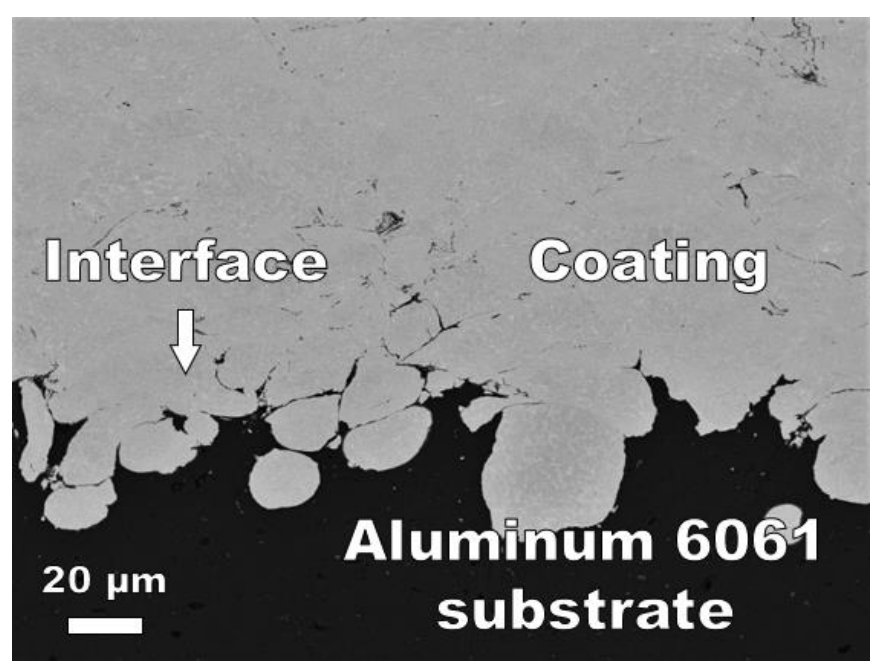

(b)

Figure 8. SEM micrograph operated in BSE scanning mode of cold sprayed Inconel 625 coating on (a) Inconel 625 and (b) Aluminum 6061 substrate. Different interface deformation patterns were observed with different types of substrate material.

\section{Conclusions}

The research was carried out to study particle velocity changes with varying spray distances and powder feed rates. From the analyses of the experimental results, the following conclusions are drawn:

- There exists a highest average velocity of $781 \mathrm{~m} / \mathrm{s}$ at an optimum spray distance of $8 \mathrm{~cm}$. The velocity increases from $744 \mathrm{~m} / \mathrm{s}$ at a $3 \mathrm{~cm}$ spray distance and then decreases beyond an $8 \mathrm{~cm}$ spray distance. This is because the powders continue to accelerate even after leaving the nozzle exit.

- The average particle velocity decreases in a linear manner at $11 \mathrm{~m} / \mathrm{s}$ per centimeter after the optimum spray distance of $8 \mathrm{~cm}$.

- The effect of powder feed rate on Inconel 625 powders is less significant; a drop in velocity of $2.77 \%$ was observed by increasing the powder feed rate from 5.45 to $92.65 \mathrm{~g} / \mathrm{min}$. This is because Inconel 625 has a high density.

- Cold spray of a single Inconel 625 particle on Inconel 625 substrate at a $20 \mathrm{~cm}$ standoff distance with pronounced jetting was achieved, indicating that deposition of cold sprayed Inconel 625 coating can be achieved at large standoff distances.

- Coatings with low porosity and high hardness were produced at the optimum standoff distance of $8 \mathrm{~cm}$ compared to the commonly used standoff distance of $3 \mathrm{~cm}$.

- Deposition on different types of substrate material was achieved by cold spraying Inconel 625 powders within the range of the parameters discussed in this study. 
The findings from this study are beneficial for cold spray repair of engineering components with complex geometry, where the standoff distance can be increased to improve the cold spray gun maneuverability. The current study focuses on understanding the effects of spray distance and powder feed rate on particle velocity. Further research is to be carried out to gain a better understanding of the microstructures and properties of coatings under different process parameters.

Author Contributions: R.G.N.: Methodology, software, formal analysis, investigation, data curation, writing —original draft preparation, writing—review and editing, visualization; K.W.: Formal analysis, investigation, data curation, writing-review and editing; S.C.T.: Funding acquisition, writing-review and editing; W.Z.: Conceptualization, formal analysis, validation, writing-review and editing, funding acquisition, supervision, project administration. All authors have read and agreed to the published version of the manuscript.

Funding: This research was funded by the National Research Foundation of Singapore, Rolls-Royce Singapore Pte Ltd. and Nanyang Technological University through grants \#002123-00002 and \#002124-00002.

Institutional Review Board Statement: Not applicable.

Informed Consent Statement: Not applicable.

Data Availability Statement: Not applicable.

Acknowledgments: This study is supported under the RIE2020 Industry Alignment Fund-Industry Collaboration Projects (IAF-ICP) Funding Initiative, as well as cash and in-kind contributions from Rolls-Royce Singapore Pte Ltd.

Conflicts of Interest: The authors declare no conflict of interest.

\section{References}

1. Yin, S.; Cavaliere, P.; Aldwell, B.; Jenkins, R.; Liao, H.; Li, W.; Lupoi, R. Cold spray additive manufacturing and repair: Fundamentals and applications. Addit. Manuf. 2018, 21, 628-650. [CrossRef]

2. Assadi, H.; Gärtner, F.; Stoltenhoff, T.; Kreye, H. Bonding mechanism in cold gas spraying. Acta Mater. 2003, 51, 4379-4394. [CrossRef]

3. Bhattiprolu, V.S.; Johnson, K.W.; Ozdemir, O.C.; Crawford, G.A. Influence of feedstock powder and cold spray processing parameters on microstructure and mechanical properties of Ti-6Al-4V cold spray depositions. Surf. Coat. Technol. 2018, 335, 1-12. [CrossRef]

4. Bhattiprolu, V.S.; Johnson, K.W.; Crawford, G.A. Influence of powder microstructure on the microstructural evolution of as-sprayed and heat treated cold-sprayed Ti-6Al-4V coatings. J. Therm. Spray Technol. 2018, 28, 174-188. [CrossRef]

5. Wu, K.; Sun, W.; Tan, A.W.-Y.; Marinescu, I.; Liu, E.; Zhou, W. An investigation into microstructure, tribological and mechanical properties of cold sprayed Inconel 625 coatings. Surf. Coat. Technol. 2021, 424, 127660. [CrossRef]

6. Wu, K.; Chee, S.W.; Sun, W.; Tan, A.W.-Y.; Tan, S.C.; Liu, E.; Zhou, W. Inconel 713C coating by cold spray for surface enhancement of Inconel 718. Metals 2021, 11, 2048. [CrossRef]

7. Hajipour, H.; Abdollah-zadeh, A.; Assadi, H.; Taheri-Nassaj, E.; Jahed, H. Effect of feedstock powder morphology on cold-sprayed titanium dioxide coatings. J. Therm. Spray Technol. 2018, 27, 1542-1550. [CrossRef]

8. Munagala, V.N.V.; Akinyi, V.; Vo, P.; Chromik, R.R. Influence of powder morphology and microstructure on the cold spray and mechanical properties of Ti-6Al-4V coatings. J. Therm. Spray Technol. 2018, 27, 827-842. [CrossRef]

9. Munagala, V.N.V.; Bessette, S.; Gauvin, R.; Chromik, R.R. Sliding wear of cold sprayed Ti-6Al-4V coatings: Effect of porosity and normal load. Wear 2020, 450-451, 203268. [CrossRef]

10. Sirvent, P.; Garrido, M.Á.; Sharp, J.; Rainforth, W.M.; Poza, P. Improving the oscillating wear response of cold sprayed Ti-6Al-4V coatings through a heat treatment. Surf. Coat. Technol. 2020, 399, 126128. [CrossRef]

11. Vidaller, M.V.; List, A.; Gaertner, F.; Klassen, T.; Dosta, S.; Guilemany, J.M. Single impact bonding of cold sprayed Ti-6Al-4V powders on different substrates. J. Therm. Spray Technol. 2015, 24, 644-658. [CrossRef]

12. Pattison, J.; Celotto, S.; Khan, A.; O'Neill, W. Standoff distance and bow shock phenomena in the cold spray process. Surf. Coat. Technol. 2008, 202, 1443-1454. [CrossRef]

13. Mauer, G.; Singh, R.; Rauwald, K.H.; Schrüfer, S.; Wilson, S.; Vaßen, R. Diagnostics of cold-sprayed particle velocities approaching critical deposition conditions. J. Therm. Spray Technol. 2017, 26, 1423-1433. [CrossRef]

14. Khun, N.W.; Tan, A.W.Y.; Bi, K.J.W.; Liu, E. Effects of working gas on wear and corrosion resistances of cold sprayed Ti-6Al-4V coatings. Surf. Coat. Technol. 2016, 302, 1-12. [CrossRef]

15. Cao, C.; Han, T.; Xu, Y.; Li, W.; Yang, X.; Hu, K. The associated effect of powder carrier gas and powder characteristics on the optimal design of the cold spray nozzle. Surf. Eng. 2020, 36, 1081-1089. [CrossRef] 
16. Meyer, M.C.; Yin, S.; McDonnell, K.A.; Stier, O.; Lupoi, R. Feed rate effect on particulate acceleration in cold spray under low stagnation pressure conditions. Surf. Coat. Technol. 2016, 304, 237-245. [CrossRef]

17. Samareh, B.; Stier, O.; Lüthen, V.; Dolatabadi, A. Assessment of cfd modeling via flow visualization in cold spray process. J. Therm. Spray Technol. 2009, 18, 934-943. [CrossRef]

18. Meyer, M.; Yin, S.; Lupoi, R. Particle in-flight velocity and dispersion measurements at increasing particle feed rates in cold spray. J. Therm. Spray Technol. 2016, 26, 60-70. [CrossRef]

19. Sova, A.; Doubenskaia, M.; Petrovskiy, P.; Smurov, I. Visualization of particle jet in cold spray by infrared camera: Feasibility tests. Int. J. Adv. Manuf. Technol. 2017, 95, 3057-3063. [CrossRef]

20. Hassani-Gangaraj, M.; Veysset, D.; Champagne, V.K.; Nelson, K.A.; Schuh, C.A. Adiabatic shear instability is not necessary for adhesion in cold spray. Acta Mater. 2018, 158, 430-439. [CrossRef]

21. Schmidt, T.; Gärtner, F.; Assadi, H.; Kreye, H. Development of a generalized parameter window for cold spray deposition. Acta Mater. 2006, 54, 729-742. [CrossRef]

22. Sun, W.; Tan, A.W.Y.; Khun, N.W.; Marinescu, I.; Liu, E. Effect of substrate surface condition on fatigue behavior of cold sprayed Ti-6Al-4V coatings. Surf. Coat. Technol. 2017, 320, 452-457. [CrossRef]

23. Tan, A.W.-Y.; Sun, W.; Bhowmik, A.; Lek, J.Y.; Song, X.; Zhai, W.; Zheng, H.; Li, F.; Marinescu, I.; Dong, Z.; et al. Effect of substrate surface roughness on microstructure and mechanical properties of cold-sprayed Ti-6Al-4V coatings on Ti-6Al-4V substrates. J. Therm. Spray Technol. 2019, 28, 1959-1973. [CrossRef]

24. Wong, W.; Vo, P.; Irissou, E.; Ryabinin, A.N.; Legoux, J.G.; Yue, S. Effect of particle morphology and size distribution on cold-sprayed pure titanium coatings. J. Therm. Spray Technol. 2013, 22, 1140-1153. [CrossRef]

25. Neo, R.G.; Tham, N.Y.S.; Wu, K.; Puthan Veetil, S.; Tan, S.C.; Zhou, W. Evaluation of powders for cold spray coatings through study of single particle impact. In International Conference on Advanced Surface Enhancement, Proceedings of the 2nd International Conference on Advanced Surface Enhancement (INCASE 2021), Singapore, 7-8 September 2021, 1st ed.; Springer: Singapore, 2022; pp. 163-167. 